\title{
CAMBIASSU

\section{A vida e o vídeo: a teoria de Carlos Nader}

\author{
Life and vídeo: Carlos \\ Nader's theory
}

\section{Gabriel Malinowski}

Professor substituto no Departamento de Comunicação Social da Universidade Federal de Juiz de Fora. Doutor em Comunicação pela Universidade do Estado do Rio de Janeiro. E-mail: gabrielmalinowski@grgmail.com 


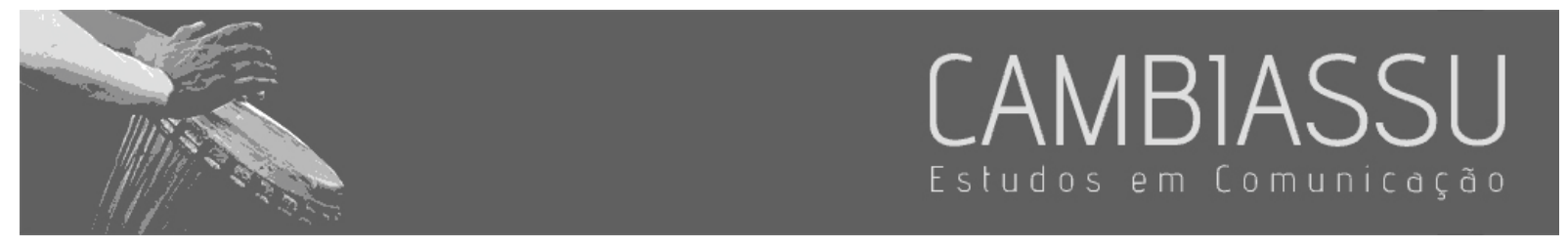

\section{Resumo}

A partir dos estudos cinematográficos da teoria do cineasta, o presente artigo investiga a prática artística de Carlos Nader. Vencedor do Festival É Tudo Verdade de 2008, 2014 e 2015, Nader é um dos documentaristas mais premiados nas últimas décadas no Brasil. Por meio de filmes, escritos e algumas entrevistas do cineasta, elaboramos três conceituações. Trata-se de uma teoria que traz reflexões instigantes sobre a produção audiovisual no mundo contemporâneo, e aposta numa relação indissociável entre a vida e vídeo. Nesse sentido, a teoria de Carlos Nader pode contribuir para os estudos com essa temática, sobretudo no campo da Comunicação.

Paldavras-chave: Teoria do cineaste; Carlos Nader; audiovisual; arquivo.

\section{Abstract}

Based on cinematographic studies of filmmaker theory, this article investigates Carlos Nader's artistic practice. Winner of the É Tudo Verdade Festival in 2008, 2014 and 2015, Nader is one of the most awarded documentarians in Brazil in recent decades. Through films, writings and some interviews with the filmmaker, we elaborated three concepts. It is a theory that brings intriguing reflections on audiovisual production in the contemporary world, and bets on an inseparable relationship between life and video. In this sense, Carlos Nader's theory can contribute to studies on this theme, especially in the field of Communication.

Keywords: filmmaker's theory; Carlos Nader; audiovisual; archive. 


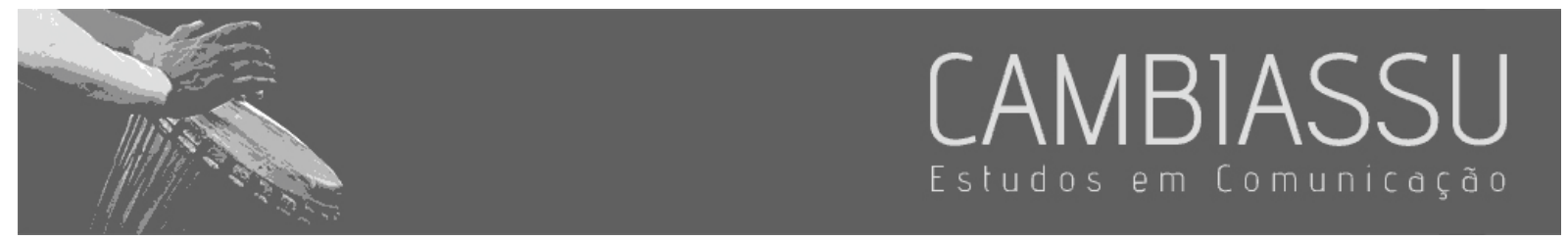

\section{Introdução}

Nos últimos anos, alguns autores têm desenvolvido um método de investigação nos estudos de cinema nomeado como teoria do cineasta. A obra de Jacques Aumont, As teorias dos cineastas, que analisa e sublinha especialmente os livros, ensaios e textos elaborados por cineastas, é uma das referências. Trata-se de cineastas que, segundo Aumont (2004, p. 13), "[...] têm uma teoria exposta na forma verbal". Para os pesquisadores que reivindicam essa perspectiva de análise, a "[...] designação [teoria dos cineastas] assume que o cineasta tem uma teoria, o que, no imediato, tem como consequência a pretensão única de apenas elaborar a teoria do cineasta" (GRAÇA et al., 2015, p. 21). Essa pretensão é uma tarefa que pode soar problemática, pois pode parecer que o "[...] cineasta necessita do apoio de um investigador para que a sua teoria se clarifique" (GRAÇA et al., 2015, p. 21). Longe de querer ocupar esse lugar, assume-se que o cineasta tem uma teoria, e o papel do estudo de cinema seria elaborar "[...] sua reflexão a partir de um diálogo próximo dessa teoria" (GRAÇA et al., 2015, p. 21).

Carlos Aziz Nader nasceu na cidade de São Paulo, em 1964. Após participar da produção de dois documentários de curta-metragem, Os Judeus-Caboclos da Amazônia (1990) e O Expresso Transiberiano (1991), ambos em parceria com Henrique Goldman (1962), mudou-se para o Rio de Janeiro para trabalhar como roteirista do programa Brasil Legal, da Rede Globo. Em 1992, lançou seu primeiro curta-metragem, $O$ beijoqueiro: portrait of a serial kisser. $O$ filme faz uma compilação de imagens de José Alves de Moura, conhecido por beijar mais de 400 figuras públicas, de jogadores de futebol a chefes de Estado. No gesto de construção de $O$ beijoqueiro, Nader propõe uma atualização da tradição antropofágica brasileira. José Alves atua como um herdeiro inconsciente do modernismo, que, na impossibilidade de comer a carne, beija suas inspirações e ídolos midiáticos. 


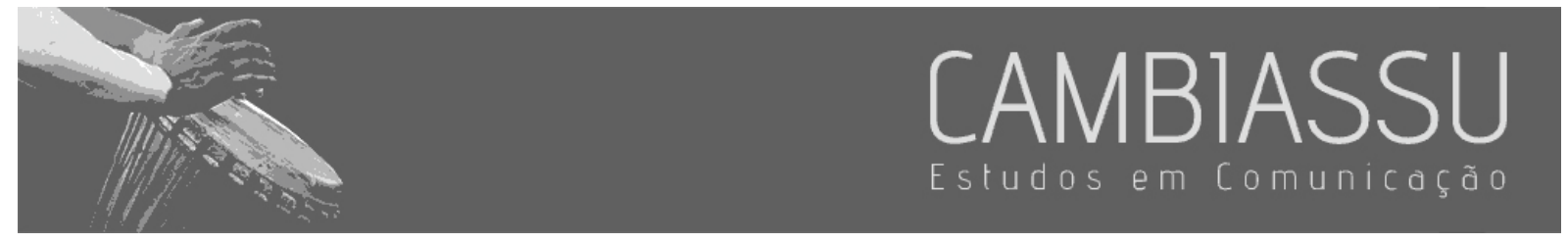

O gesto antropofágico, tematizado na figura de José Alves, constitui também o modo de trabalho de Carlos Nader neste filme e em boa parte de sua obra. A apropriação e transformação de um material audiovisual já existente, inclusive imagens suas já utilizadas em outros trabalhos, são práticas que o cineasta desenvolverá de forma exemplar nos longas Pan Cinema Permanente (2008), Homem Comum (2014) e A Paixão de JL (2015), cada um à sua maneira. Além desses longas, Nader possui outros curtas-metragens e longas, como Preto e Branco (2004) e Chelpa Ferro (2009), além de trabalhos encomendados por diversas instituições.

Trovoada (1994), Carlos Nader(1996) e Concepção (2001) são três desses filmes de curta-metragem que, segundo o cineasta, formam uma trilogia sobre o Tempo, o Ser e a Morte. Podemos notar, tanto na forma quanto no conteúdo desses filmes, elementos que serão desdobrados em seus trabalhos posteriores. Trovoada discute e problematiza o tempo: o tempo da vida, o tempo das imagens. Os outros dois curtas, Carlos Nader e Concepção, estão mais centrados em questões de identidade e alteridade. (MALINOWSKI, 2020, p. 16).

É a partir desses três filmes, principalmente, que iremos propor alguns pontos e questões sobre uma possível teoria de Carlos Nader, além de sugerir, ao final, sua relevância para o campo da Comunicação.

\section{Carlos Nader (1996)}

Analisemos, primeiramente, o curta-metragem Carlos Nader de 1996. Conforme anunciava uma revista especializada à época do lançamento: "[...] o que à princípio parece uma confissão, transforma-se em um documento sobre a busca da identidade, ou, mais ainda, em uma discussão sobre a busca das identidades" (CESANA, 1999, p. 29). O curta começa com uma imagem caseira, que lembra muito certa estética de vlogs, feita de modo improvisado e num ambiente doméstico. Nader está sentado no chão de seu quarto perto de uma estante e de uma tomada. Ele então diz à câmera: "Eu tenho um segredo, que é o segredo mais íntimo que eu tenho. É o maior segredo da minha vida. Eu 


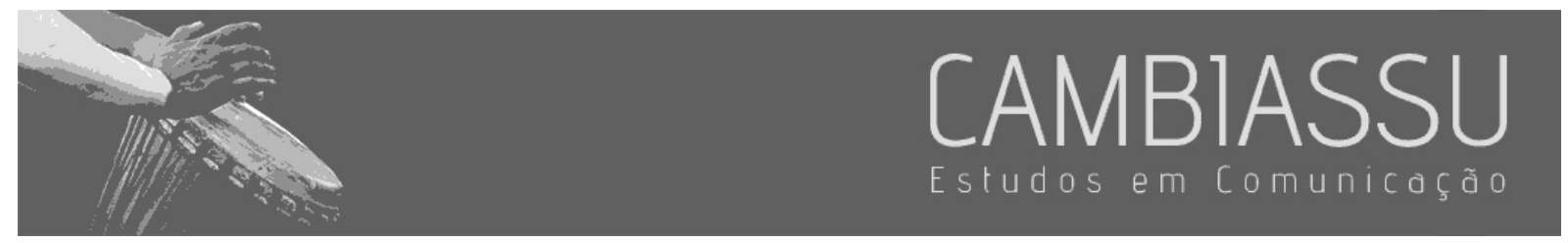

nunca contei esse segredo para ninguém e eu queria contar agora, aqui para a câmera" (informação verbal). Entretanto, quando começa a contar esse segredo, não ouvimos mais nada. Na visão de Cícero (2009, não paginado), “[...] o segredo não pode ser dito em linguagem prosaica. O vídeo prossegue. O segredo está no mundo. O vídeo o prova". Com efeito, se existe um segredo, esse segredo é mostrado nas imagens que seguem. O segredo são as imagens e sons do mundo. Aquilo de mais íntimo que existe para o realizador é mostrado numa sucessão de imagens heterogêneas, uma colagem com depoimentos, performances e paisagens. Nota-se, nesse jogo, uma primeira operação marcante nos filmes de Nader, que será lapidada e desenvolvida ao longo de sua trajetória: a variação de escalas que acontecem entre eu e o outro.

Carlos Nader é uma autobiografia às avessas que nega qualquer gesto de transparência. Acompanhamos o gesto subjetivo do filme, certamente, mas transpassado por uma subjetividade que só pode ser vivida e explorada em sua relação com as subjetividades-mundo, em um jogo de máscaras retroalimentado por imagens que estão para além do quarto do cineasta. Segundo o diretor, "Carlos Nader tem o meu nome, mas, como todos os meus outros filmes, aponta a câmera para o mundo" (NADER, 2016, p. 114). Ainda segundo o diretor, "Carlos Nader é um filme sobre mim na mesma medida que qualquer outro filme meu é sobre mim. Toda obra é também sobre seu autor." (NADER, 2016, p. 114). Ele então resume essa relação em relação ao vídeo: “Carlos Nader realmente não acredita no limite entre eu e o Outro. Mais que isso, o vídeo acredita que eu é o outro. E o que nos une é um vazio profundo, intenso, assustador, mas também libertador: o mistério da existência." (NADER, 2016, p. 115).

Com efeito, esse mistério da existência, que não pode ser nomeado, é atravessado por imagens de diversas escalas e materialidades e de diferentes contextos. Não à toa, a religiosidade é tangencialmente matizada em sua filmografia e seus registros. De modo geral, em seus filmes, paisagens e personagens estão conectados aos diversos rituais: ao círio de Nazaré, ao dia de lemanjá, 


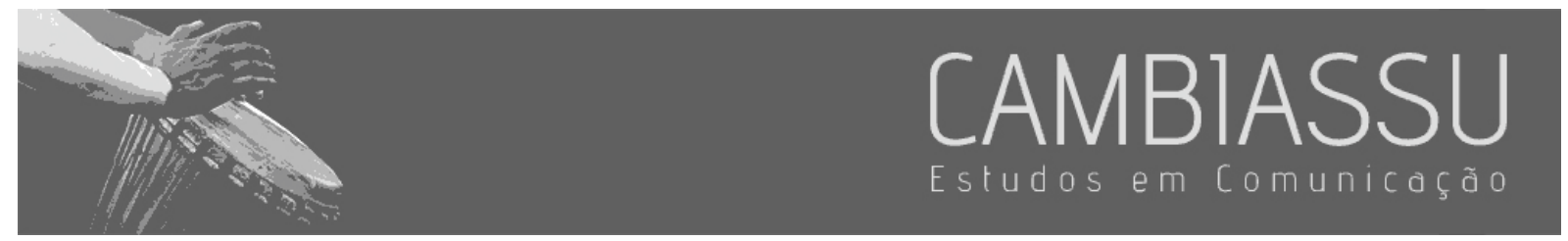

às práticas cristãs. Conjuga-se, na montagem desses materiais, certa fé nas imagens que conecta aquilo que há de mais íntimo e sagrado (o segredo que ele quer contar) com as visualidades da ordem do coletivo, da comunidade, a partir de conexões culturalmente mediadas. Os filmes, assim, parecem vislumbrar uma transcendência que conecta o mundo dos vivos ao mundo das imagens técnicas e viceversa.

O que eles [os filmes] documentam não é uma pessoa. É um encontro. O meu encontro com essa pessoa. Isso acontece bem explicitamente e imediatamente em alguns trabalhos, como Homem Comum e mais implicitamente e mesmo postumamente em outros como $A$ Paixão de $J L$. Mas todos os filmes retratam o compartilhamento de uma experiência. Esses filmes não são sobre alguém. São com alguém. Pan cinema é com o Waly. Homem Comum é com o Nilson. A Paixão é com o Leonilson. No fundo, esses filmes tentam emular o que nos une, todos, humanos, que é compartilhar a mais intensa e misteriosa das experiências, a de estar vivo. É o que nos resta. Já que não fazemos a menor ideia daquilo a que se destina o existir, podemos pelo menos compartilhar a experiência de existir. Não vejo sentido maior que esse na arte nem na vida. (NADER, 2016, p. 115).

O filme, na perspectiva lançada pelo próprio cineasta, não seria um elemento de representação: “[...] esses filmes não são sobre alguém” (NADER, 2016, p. 115), ele afirma. O filme seria um gesto para conectar experiências. Trata-se de experiências que são mediadas (ou medidas) por imagens; a percepção da vida como algo fortemente amalgamado ao vídeo (ou à mídia, de modo geral). Dentro das próprias obras, e também em seus escritos e suas entrevistas, essa relação é explorada de inúmeras formas.

\section{A teoria de Nader}

Para desenvolver certas questões da teoria de Nader, é necessário, antes, notar alguns elementos importantes que perpassam esse campo de estudo. Originalidade e autoria são dois conceitos importantes na teoria dos cineastas. Isso porque o cinema de cunho mais autoral e que 


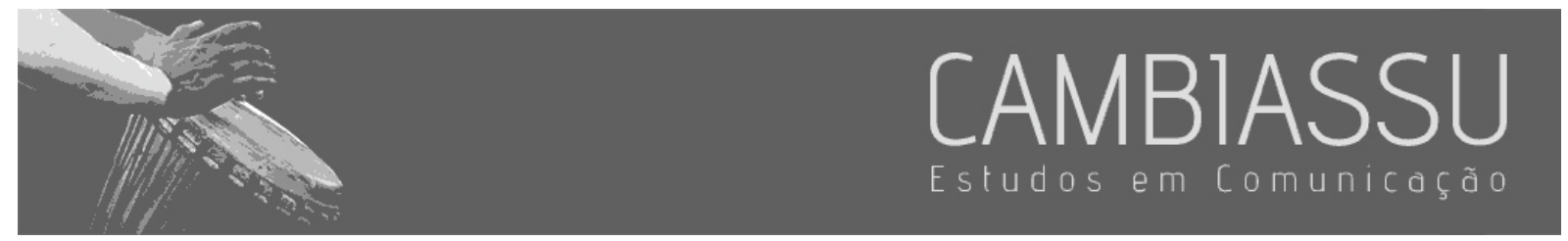

trabalha com gestos de originalidade não seria possível sem um gesto reflexivo e teórico. Conforme enfatizam Graça et al. (2015, p. 23):

[...] a partir desses dois conceitos temos a necessidade de assumir que um artista, cineasta ou de outra linguagem, reflete teoricamente sobre as suas obras, pois não poderia ser original ou não poderia estabelecer um estilo caso não desenvolvesse reflexões sobre os seus atos criativos.

Deve-se notar, contudo, que a teoria do cineasta não se confunde com a teoria do autor. "Devido ao fato de serem termos próximos e muitas vezes entendidos como sinônimos, ocorre a possibilidade de serem entendidos como termos intermutáveis, o que geraria uma imprecisão metodológica" (GRAÇA et al., 2015, p. 26-27).

A questão autoral no cinema, como se sabe, ganhou força a partir dos filmes que formaram a Nouvelle Vague francesa. Além disso, criada a partir de março de 1951 por Jacques Doniol-Valcroze, André Bazin e Lo Duca, a revista francesa Cahiers du Cinéma estará no centro das discussões sobre as teorias de cinema de autor e será contemporâneo, não coincidentemente, a um conjunto de filmes que tem a figura de Jean-Luc Godard como referência. Como afirma Wollen:

A teoria do autor desenvolveu-se de forma bastante fortuita; nunca foi elaborada de modo programático, num manifesto ou numa declaração colectiva. Como resultado temos que pode ser interpretada e aplicada segundo linhas bem latas; diferentes críticos aprofundaram métodos de certo modo diferentes dentro de uma estrutura fluida de atitudes comuns. (WOLLEN, 1984, p. 79).

Além disso, outro fator preponderante na concepção da Nouvelle Vague, e em outros movimentos que partiam das premissas autorais, como do Cinema Novo brasileiro, será certa inspiração no Neo-Realismo Italiano. As questões de produção e de estética difundidas nos filmes italianos do pós-guerra terão forte impacto em muitas culturas cinematográficas modernas. Foi a partir do Neo-Realismo que começou a ser debatido o conceito de autor no cinema. 


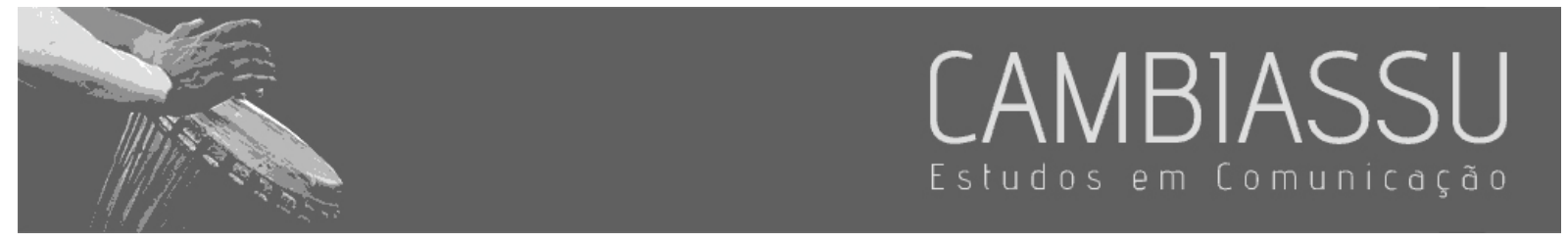

Contudo, a teoria do "cineasta" teria um escopo maior que o conceito de autor, pois "[...] desde roteiristas/argumentistas, a compositores, a editores de som e montadores, todos eles são aqui considerados cineastas" (GRAÇA et al., 2015, p. 27). Além disso, a teoria dos cineastas seria uma prática de filtragem e refinação, ou seja, um "[...] exercício a posteriori da teoria elaborada pelo autor" (GRAÇA et al., 2015, p. 27), que tem como objetivo "extrair o máximo de riqueza teórica sem, no entanto, nos deixarmos enredar por teias de ego ou outras armadilhas presentes no lado performativo que implica a elaboração de teoria por parte de um cineasta (tanto mais um autor)" (GRAÇA et al., 2015, p. 27-28).

Em relação à prática cinematográfica e aos filmes de Nader, poderíamos apontar três pontos centrais. O primeiro estaria relacionado a certo modo de operar, na montagem das imagens e nas variações de escalas entre o eu e o outro. Essa relação, nos filmes, é efetivada por dois regimes de imagens: do arquivo pessoal de Nader, do arquivo-mundo do cinema e da televisão. Trata-se de um gesto de produção e exibição que aposta no rompimento de fronteiras. O segundo ponto é a noção de Plano Imaginal que o cineasta reconhece em sua forma de ver o mundo, de realizar filmes, de construir seus personagens. Essa noção é desenvolvida em certos escritos e entrevistas, mas se torna clara nas próprias obras fílmicas. E, como último ponto, são as operações temporais de sua montagem a partir das relações de escalas nesse plano imaginal.

\section{Os regimes de imagens}

Na base dos estudos filosóficos de Gilles Deleuze a partir do cinema, há uma diferenciação entre dois regimes de imagens: as imagens-movimento e as imagens-tempo. Deleuze desenvolve, a partir do repertório de Henri Bergson, um trabalho filosófico-cinematográfico original sobre percepção e estética. De um ponto de vista cinematográfico, o trabalho sugere uma divisão marcante na história do cinema, que tem como marco central o fim da Segunda Guerra Mundial. Alguns cineastas, na 


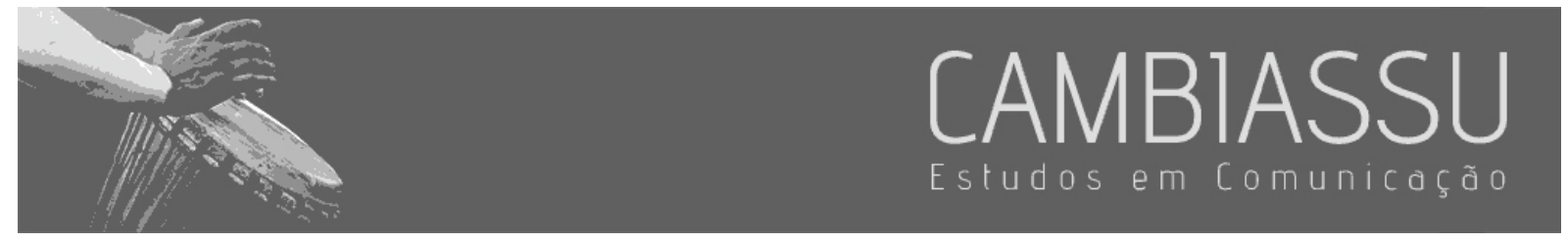

acepção deleuziana, encerram formas de pensamento em seu ato de criação, que, por sua vez, estão conectadas a regimes estético-perceptivos específicos de cada época. Imagem-movimento e imagemtempo são regimes de imagens que se relacionam às formas dos cineastas produzirem e pensarem as imagens no mundo. De um regime que seria fortemente sensório-motor, uma imagem-movimento (DELEUZE, 1985), o fim da Segunda Guerra provoca uma alteração profunda nas crenças, nas formas de olhar e na forma de encarar as imagens, fazendo nascer as imagens-tempo (DELEUZE, 2005).

Pode-se dizer que o cinema de Carlos Nader utiliza, ou faz notar, dois regimes de "imagens de arquivo". Assim como nos regimes deleuzianos, trata-se de formas de produção e exibição de imagens, ou seja, os contextos nos quais elas se apresentam. Entretanto, no caso de Nader, essas imagens já estão no mundo e suas distinções são de outras ordens.

Em primeiro lugar, não há uma distância histórica entre elas. Os dois regimes de imagens de arquivo de Nader foram produzidos em um mesmo período, a segunda metade do século XX. Suas diferenças perpassam, sobretudo, as esferas do público e do privado. Em um dos regimes, temos imagens que se relacionaram, de forma diversa, a uma coletividade. São imagens provenientes do cinema e da televisão. Em outro ponto, temos imagens que foram produzidas e circuladas nas bordas, na periferia dos grandes sistemas institucionalizados, incluindo os espaços privados do lar. Essa relação, principalmente nos três longas que mencionamos, é o modo de compor a história dos personagens retratados. É na relação desses dois conjuntos ou regimes de imagens de arquivo que se instaura um possível discurso fílmico ou uma história dos personagens.

A construção de filmes a partir da relação entre esses regimes acontece desde $O$ Beijoqueiro. Porém, são os três longas-metragens citados que permitem notar as potências e implicações desse tipo de montagem. Em Pan-Cinema Permanente, Homem Comum e $A$ Paixão de JL, há um encadeamento e uma reordenação arqueológica de recursos audiovisuais oficiais, provenientes de 


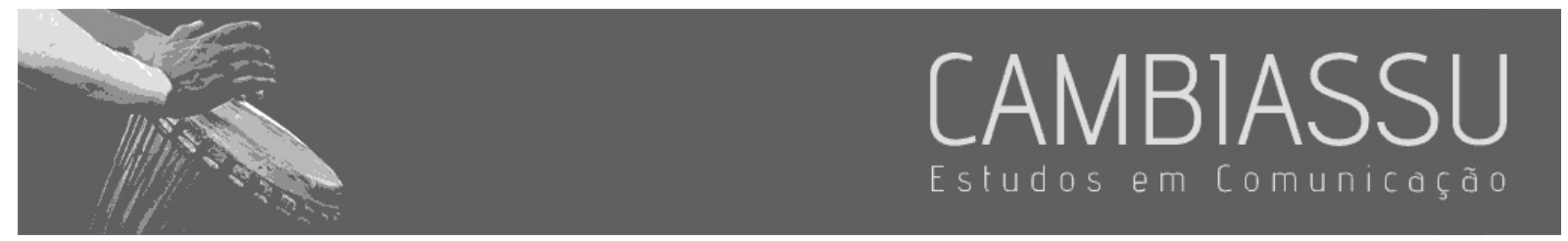

produções institucionalizadas, tais como a televisão e o cinema, além de materiais mais periféricos, feitos de modo mais amador, caseiro, experimental. Trata-se de imagens que operam entre escalas distintas, de um regime de imagens feito para circular entre um grande público até imagens de destino incerto, feitas a partir de um desejo de registro, entre materiais bem conhecidos com imagens e sons provenientes de arquivos inéditos. Muitas vezes, são imagens e sons reciclados de seus próprios trabalhos. Um mesmo plano pode ganhar novos sentidos e intenções em uma nova montagem. Em uma entrevista, ao falar sobre a prática de montagem, Nader deixa essas relações evidentes:

Eu tive esse tempo necessário no filme com o Leonilson. A mistura ali é mais fina. Dá para dizer que tudo que caracteriza o meu trabalho, na visão dos outros ou na minha, está ali: a mistura da chamada ficção com a chamada realidade, a polifonia, o encontro artístico-afetivo, a mistura de linguagens, o experimentalismo indissoluvelmente relacionado à experiência de vida, o amálgama entre o que há de mais público e o que há de mais privado (NADER, 2016, p. 116).

\section{0 plano imaginal}

Mais do que notar a presença desses regimes de imagens de arquivo, é fundamental acompanhar como eles são operados no pensamento e na criação de Carlos Nader. A variação de escala que esses regimes colocam em evidência é algo "muito consciente" no trabalho do cineasta, como ele mesmo confirma. Os dois regimes de imagem, ao intercalarem as dimensões pessoais e coletivas e ordenarem as imagens de arquivo, tornam possivel uma construção historicamente mais subjetivada, uma forma de produção histórica perpassada por ordenamentos da vida privada. Com efeito, são características marcantes que aproximam esses três filmes. Trata-se de um modo de compor um diapasão intersubjetivo, que ora relaciona o cineasta ao personagem documentado, ora o personagem ao coletivo, às subjetividades-mundo, às imagens coletivas.

Em um texto escrito há mais de vinte anos, Nader aborda certa visão mítica dos mídia e percebe a câmera como uma peça fundamental para operar certos milagres nessa religião das máquinas de 


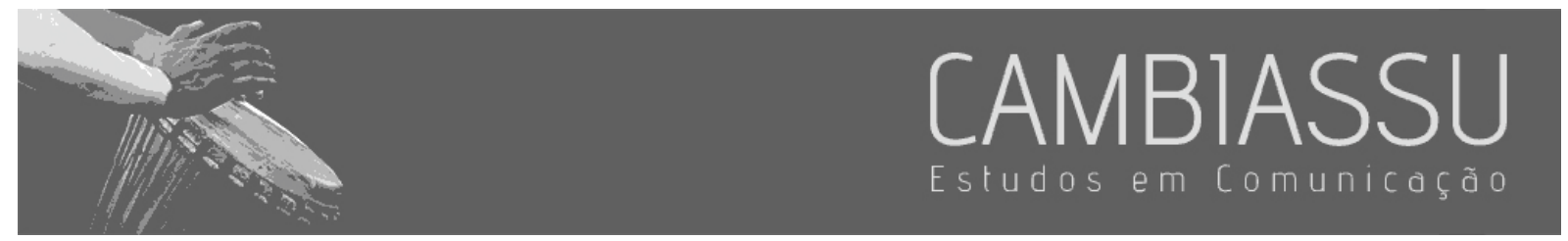

imagem. Ele acompanha o Círio de Nazaré com uma equipe de filmagem. A magnitude da câmera frente à multidão de fiéis é colocada nos seguintes termos:

Então o milagre. O Henrique Goldman, nosso diretor, ordena e o John Weitzman, cinegrafista, coloca a câmera nas costas. O milagre. Eles avançam mosaicamente. $O$ mar abre. O mar abre fácil. Eu vou atrás. Nós temos salvo conduto. A câmera. Os fiéis suspendem o transe por um instante. Aquilo erguido nas costas do John é um outro ícone religioso, não só mais o mero captador eletrônico de imagens, mas em si uma imagem religiosa de aura e carisma suficientemente intensos para desviar a atenção dos fiéis, ainda que por alguns instantes, da imagem que está no interior da corda. (NADER, 1999, não paginado).

Nader explora, nesse texto, um imaginário e uma retórica religiosa acerca dos mídia. Nesse sentido, ele dialoga com certas conformações, certos modos de perceber o desenvolvimento tecnológico ao longo da modernidade. Como pontua Erick Felinto:

[...] o discurso sobre as tecnologias - e de modo ainda mais evidente o discurso sobre as chamadas novas tecnologias de informação e comunicação [...] - encontra-se recheado de tropos místicos e religiosos sugestivos da transcendência das limitações humanas. (FELINTO, 2003, não paginado).

Com efeito, as práticas religiosas que integram de modo categórico a construção de Waly, Nilson e Leonilson, encontram, nesse texto, uma relação intrínseca com as imagens técnicas que nos cercam.

No texto, a filmagem do Círio de Nazaré, uma visita ao Cristo Redentor, as gravações da festa para lemanjá, em Salvador, são modos de refletir acerca do papel da câmera na produção de uma ordem visual-religiosa. As três filmagens em universo religioso servem de mote para uma reflexão sobre a "mítia" (mito e mídia) que envolve o universo das imagens técnicas. Entretanto, essa mítia não atua como algo que domina o humano, nem tampouco faz dela algo transcendental. A mítia que Nader sugere é incorporada ao homem comum. Para embasar essa perspectiva no texto, o cineasta faz uma referência ao teólogo Ibn Arabi, que o artista Bill Viola, no alto do Cristo Redentor, descreve à Nader: 


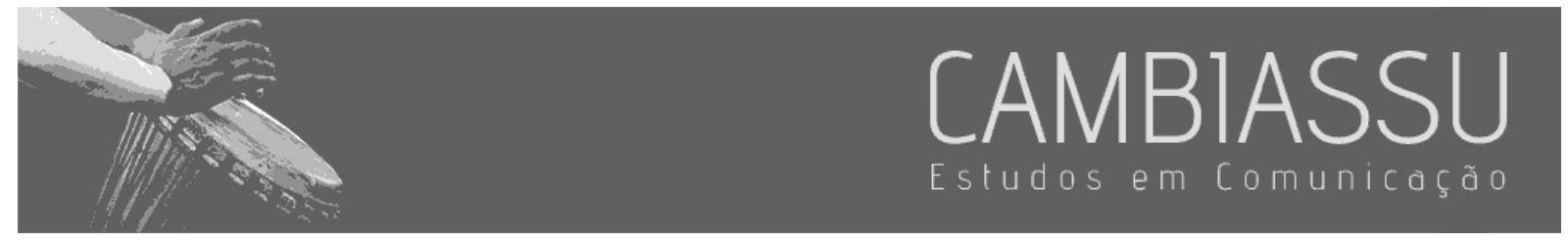

"Viola me diz que entre suas maiores fontes de inspiração está Ibn Arabi, teólogo do califado de Córdoba, mente mestra do sufismo medieval, autor de uma das mais sofisticadas obras da tradição profética" (NADER, 1999, não paginado). Nader então explicita essa "lâmpada mágica" que Ibn Arabi acende na Idade Média. Trata-se de um "farol teológico" que divide a totalidade do universo em três planos:

Plano Um: o mundo como o vemos já, as coisas agora, o espaço-tempo físico e tangível do aqui agora. Plano Três: o plano divino ou Deus ele-mesmo, que é luz e só luz, totalmente isento de qualquer positividade, vazio de qualquer coisa material ou virtual. (NADER, 1999, não paginado).

Entre o Plano Um e o Plano Três há o Plano Dois, que permeia os dois anteriores e que Ibn Arabi nomeia como Plano Imaginal, "[...] o reino da Imaginação Criativa, o lugar onde Imaginar é um verbo realmente ativo, onde Imaginar é criar imagens que têm uma existência tão real quanto as do mundo físico" (NADER, 1999, não paginado).

Nader nota que, no Plano Imaginal de hoje, as imagens técnicas - as imagens das câmeras , convivem com as imagens que habitam os indivíduos - as imagens do sonho, as memórias -, por meio de pontes que as conectam.

Além de Maomé, Jesus, Moisés, Elias-Kidhr, habitam o Plano Imaginal todas as coisas que se imaginam, literalmente. Habitam o plano Imaginal ao mesmo tempo todos os sonhos, todos os seres mitológicos, todas as pessoas e coisas que estão em outro lugar do espaço, todos os personagens e objetos do passado ou futuro (NADER, 1999, não paginado).

Nesse sentido, os aparelhos atuariam como uma forma de ligar o plano físico ao plano divino, ou seja, os aparelhos seriam as formas contemporâneas de produzir o plano imaginal.

Independentemente de qualquer cenário social específico, a câmera, para efetuar seus milagres, dissolve a separação entre as coisas do mundo que são 'reais' e as coisas do mundo que 'não são reais'. O vídeo é uma máquina de criar imagens, uma 


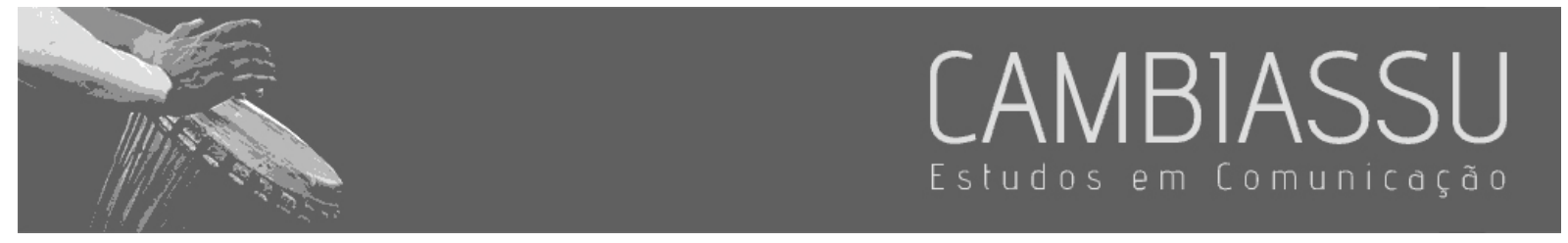

máquina de imaginação. Toda a virtualidade é minha. Tudo acontece agora (NADER, 1999, não paginado).

Além da câmera, na ponta da produção, é também a televisão, do ponto de vista do observador/espectador, que compõe esse plano imaginal. Nesse ponto, Nader faz uma relação entre televisão e inconsciente, integrando aspectos coletivos e individualizantes na formação do plano imaginal. Ele escreve:

A televisão é tão coletiva quanto o inconsciente. Pensem num sonho que vocês tiverem. O sonho não é uma série de imagens que nós editamos como se fosse um documentário sobre nós mesmos? O sonho de uma só pessoa é a forma mais individual de imagem e têm uma gramática virtualmente idêntica àquela da forma mais pública e notória de imagem, aquela que aparece nas telas da televisão. (NADER, 1999, não paginado).

Em uma entrevista, Nader complementa dizendo que:

Há uns vinte anos eu escrevi [...] que a TV era tão coletiva [...] quanto o inconsciente, ou seja, que a TV sou eu. Claro, era uma boutade. Mas a ideia central era a de que uma imagem considerada pública apropriada por mim é tão minha quanto uma imagem considerada privada (MALINOWSKI, 2020, p. 27).

No curta Concepção, por exemplo, há um momento em que a imagem da "mãe de seu filho", como ele nomeia a personagem, é mostrada de costas com uma televisão à sua frente. Opera-se uma montagem então que parece colocar em questão essa ideia central. Ao intercalar a imagem da mulher com as imagens televisivas de forma muito rápida, há um efeito de unidade entre elas, confundindo as imagens televisivas com a imagem da mulher. É como se, naquela montagem, a mulher se apropriasse daquela imagem, como se ela se tornasse a imagem da televisão e a televisão, nesse mesmo movimento, vivesse na cabeça daquela mulher.

\section{Trovoadas de tempo}

O terceiro ponto importante na teoria de Carlos Nader é a forma de compor e perceber o tempo. O próprio modo como Pan-Cinema Permanente, Homem Comum e A Paixão de JL foram produzidos 


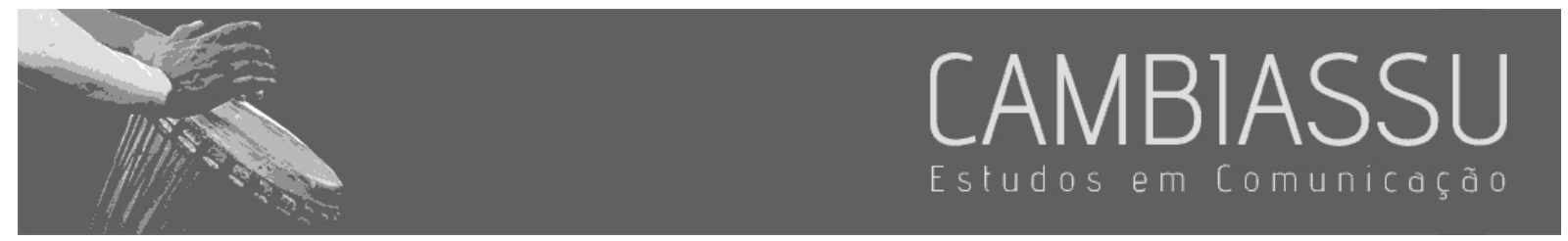

já é um início de como o tecido do tempo é operado na criação em Nader. Todos os três filmes nascem de processos de produção de arquivos que se desenrolam por anos e décadas. Além disso, os efeitos de montagem e também das temáticas abordadas possibilitam uma incursão teórica, à medida em que o cineasta trata o tempo como um elemento com várias implicações nessa relação da vida com o vídeo.

No curta-metragem Trovoada (1994), a temática do tempo é trabalhada de duas maneiras. Primeiramente como tema, por meio de discursos de Bill Viola, Waly Salomão e Antônio Cícero. Já no início do filme, há uma narração de Bill Viola:

O tempo é biológico. O tempo é feito pelo ritmo do metabolismo. O tempo é o desdobramento do processo celular. É a transcrição da proteína. A construção da membrana. O transporte de materiais. O tempo é um fenômeno criado pela própria vida. Tempo, temperatura e estado atmosférico são todos relacionados através do conceito de mudança. Eles são de fato a variedade da mudança. (TROVOADA, 1994 apud MALINOWSKI, 2020, p. 29).

Essa perspectiva do tempo como uma variedade de mudança pode ser desdobrada, no campo do cinema, no processo de montagem de imagens. Esse processo de montagem, tal como o compreendemos, deve ser visto não apenas como a técnica cinematográfica, mas qualquer processo que produz uma "variedade de mudança" entre imagens. O ato de acompanhar ou assistir a uma série de vídeos em plataformas digitais como Instagram ou YouTube é um modo de montagem. Nos filmes de Nader, a "variedade de mudanças" é instaurada na própria variedade de materiais utilizados. Tratase de uma operação em que as ligações entre as imagens e sons ultrapassam qualquer efeito de causalidade ou de linearidade. Daí, a sensação de acompanhar um ritmo nessas imagens do passado. Trata-se de um ritmo que nos apresenta o tempo das imagens. Essa dinâmica do ritmo é desenvolvida com Bill Viola nos áudios de Trovoada. Ele nos lembra que o ritmo é uma qualidade explorada em todas atividades humanas. 


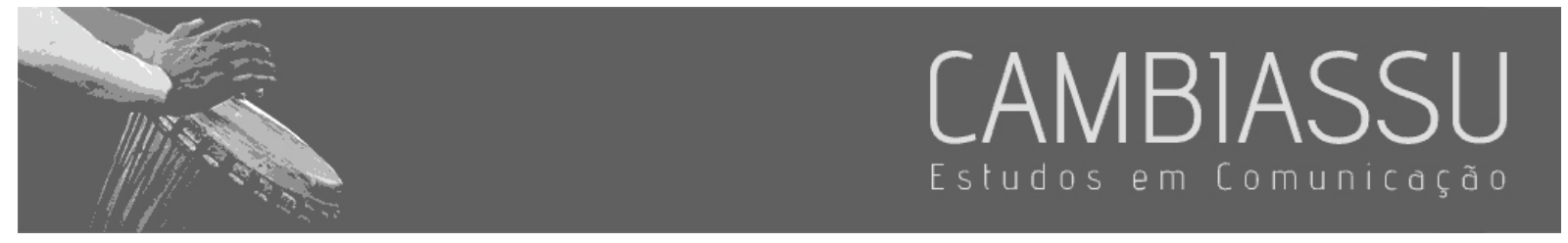

Eu acho que o conceito de causa e efeito, ação e reação, conduz nossas sociedades no mundo industrializado. Mas nos deu uma visão distorcida de tempo. O coração batendo é a origem de toda a música, é a origem do tempo, da noção de tempo, é a noção de ritmo em todas as atividades humanas. E o tambor, o bater do tambor, é a expressão física e representação do tambor batendo. (TROVOADA, 1994 apud MALINOWSKI, 2020, p. 29).

O ritmo nos filmes de arquivo de Nader, o ritmo dos sons, o ritmo das narrações, o ritmo das imagens, fragmentadas e segmentadas, promovem, assim, uma experiência temporal calcada em uma composição de imagens de diferentes épocas, de diferentes tempos. É um ritmo que fala, de certa forma, de operar esse imenso arquivo das imagens técnicas. O ritmo que essa composição audiovisual provoca pode ser dimensionada em relação a nos relacionarmos com as imagens do passado. Os filmes evidenciam certa complexidade na forma de apreender o tempo, ultrapassando sua compreensão linear de causa e efeito. Waly Salomão afirma em certo momento de Trovoada: "a minha visão se toca bastante com essa visão não linear, é uma visão onde perpendiculares de outros tempos invadem, penetram". O tempo que os filmes dão a ver é criador de perceptos, e conduzem as formas de criação/individuação. Waly Salomão de novo, em outro momento, lê parte do texto significativamente intitulado Na esfera da produção de si mesmo:

[...] E o vir a ser, e o me tornar, e o me tornar, e o me tornar, e o futuro, e o passado, e o perdido fundido no presente deste dia dado que toco e deste dia dado que me toca. Todo o nada, nada, nada pode deixar passar de leve o vento por entre as frestas dos meus dedos [...] os passos leves do vento por entre nos interstícios. (TROVOADA, 1994 apud MALINOWSKI, 2020, p. 30).

Pode-se dizer então que, além do conteúdo, a tematização desse tempo reticular, intensivo, não linear dá-se na própria forma de construção de certos filmes de Nader. Em Trovoada, especificamente, há o recurso da montagem muito rápida, com imagens que aparecem e somem instantaneamente, como se fossem raios. Trovoada é um filme feito com imagens e sons que aparecem e desaparecem ao ritmo dos trovões. São lampejos de imagens que nos assombram em montagens inesperadas, nas quais percebemos a qualidade de uma duração que nos integra e nos 


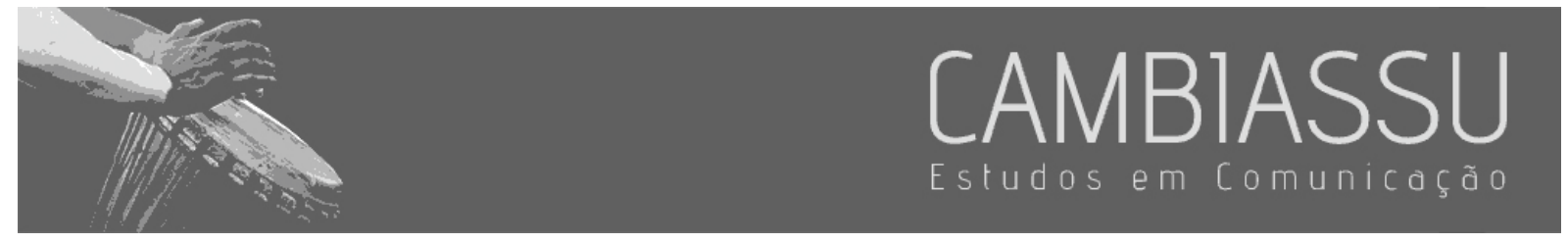

conecta com aquilo que foi, aquilo que não existe senão na materialidade fugidia das formas de luz que nos alcançam.

\section{Considerações finais}

Seria interessante, para concluir, fazer uma breve articulação da teoria de Nader e suas possíveis contribuições para o campo da Comunicação. Como foi pontuado, os filmes de Nader são formados por uma prática de reapropriação e montagem de imagens e sons provindos de diversas mídias. Trata-se de um gesto que dialoga com certas dinâmicas das chamadas "novas tecnologias da comunicação" e suas formas de operar arquivos de imagem e som heterogêneos, que borram fronteiras e reconfiguram as dimensões do público e do privado. Sabendo que a obra de arte não é autônoma, mas está inserida no mundo da imagem do qual faz parte, podemos afirmar que a teoria do cineasta reflete parte da política visual de nossos tempos. Essas operações artístico-conceituais do realizador parecem possibilitar uma leitura sofisticada dos modos de funcionamento dos dispositivos audiovisuais contemporâneos.

O que a teoria de Nader parece apontar é que a vida e o vídeo estão amalgamados, compartilhando um mesmo espaço-tempo de realidade, interpenetrando suas dimensões materiais e imateriais. Por isso, a relação dos aparelhos, das máquinas de imagem, com seus personagens é realizada de modo forçosamente cibernético. Não há uma humanidade corrompida pelo vídeo, pelos gravadores ou qualquer outro ambiente midiático, mas antes uma composição onde as fronteiras não podem ser demarcadas. Em Pan Cinema Permanente, a figura de Waly Salomão, fortemente midiática, é explorada em diversas nuances, mas sobretudo pelo modo como o poeta se portava perante as câmeras. Em $A$ paixão de $J L$, as memórias de José Leonilson são reconstruídas a partir dos diários sonoros registrados pelo artista. Em Homem Comum, de modo ainda mais explícito, é a câmera que produz certa potencialidade na vida ordinária de Nilson de Paula. 


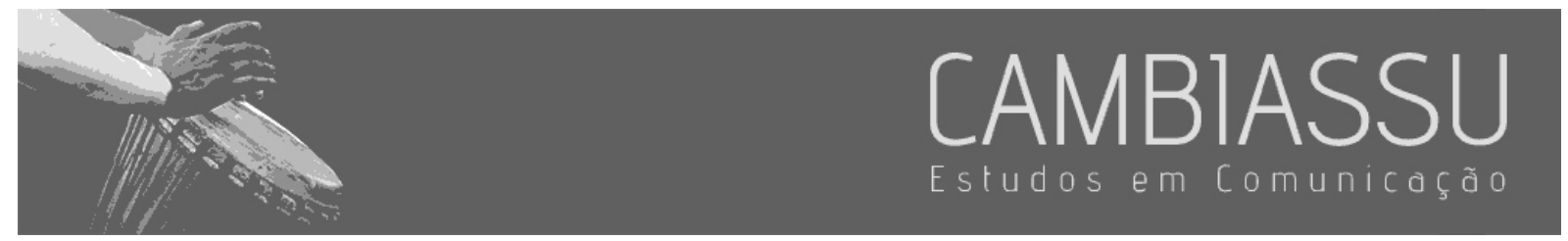

À propósito, na parte final de Homem Comum, em uma conversa com Nilson, o cineasta fala ao caminhoneiro: "Se tem uma coisa que eu fico me perguntando sempre é por que esse filme fica continuando $[\ldots]$ há quase vinte anos. Por que? [...] O que esse filme fez acontecer entre a gente, Nilsão?" (informação verbal). Então, Nilson interrompe e diz: "Carlos, eu vou te dizer uma coisa:" (informação verbal), mas não consegue dizer mais nada, pois parece tomado por uma emoção muito intensa. Trata-se de um silêncio que, em certa medida, remete ao silêncio instaurado pelo diretor após anunciar a revelação de um segredo, no curta-metragem Carlos Nader. Aquilo que não é falado, em ambos os casos, é uma ausência que o vídeo se encarrega de preencher: "Nós dois precisamos desse filme para viver. Nós precisamos da câmera para viver" (informação verbal), atesta Nader à Nilson em outro momento do filme.

\section{Referências}

AUMONT, Jacques. As teorias dos cineastas. Campinas: Papirus, 2004.

CARLOS Nader. Produção de Carlos Nader. [S.I.: s.n.], 1999. 1 DVD (16 min).

CESANA, Marcos. Um zoom no sagrado. Revista Videomaker, [Lagoa Santa], ano 3, n. 28, p. 28-30, mar. 1999.

CíCERO, Antônio. Os vídeos poéticos de Carlos Nader. Folha de São Paulo, São Paulo, 4 abr. 2009. Disponível em: https://www1.folha.uol.com.br/fsp/ilustrad/fq0404200929.htm. Acesso em: 2 jun. 2021.

DELEUZE, Gilles. Cinema 1: a imagem-movimento. São Paulo: Brasiliense, 1985.

Cinema 2: a imagem-tempo. São Paulo: Brasiliense, 2005.

FELINTO, Erick. A religião das máquinas: pressupostos metodológicos para uma investigação do imaginário da cibercultura. Texto apresentado no GT Tecnologias Informacionais de Comunicação e Sociedade, no XII Encontro Nacional da COMPÒS, em 2003.

GRAÇA, André Rui; BAGGIO, Eduardo Tulio; PENAFRIA, Manuela. Teoria dos cineastas: uma abordagem para a teoria do cinema. Revista Científica/FAP, Curitiba, v. 12, p. 19-32, jan./jun. 2015.

HOMEM comum. Produção de Carlos Nader. [S.I.]: Vitrine Filmes, 2015. 1 DVD (93 min).

MALINOWSKI, Gabriel Gesualdi. Montagens do público e do privado no arquivo audiovisual: imaginação histórica e cultural do fragmento a partir de filmes de Carlos Nader. 2020. Tese (Doutorado em Comunicação) Programa de Pós-graduação em Comunicação, Universidade do Estado do Rio de Janeiro, Rio de Janeiro, 2020.

NADER, Carlos. Mítia. Revista Trip, [São Paulo], out. 1999.

NADER, Carlos. Entrevista com Carlos Nader. Revista Pós, Belo Horizonte, v. 6, no 1, p. 110-117, maio 2016.

WOLLEN, Peter. Signos e Significação do Cinema. Lisboa: Livros Horizonte, 1984. 